\title{
Percutaneous Coronary Intervention with Everolimus-Eluting Bioresorbable Vascular Scaffolds in Diffuse Coronary Artery Disease: Current Knowledge and Future Perspectives
}

\author{
Giulia Masiero', Luca Nai Fovino', Alessandro Schiavo', Daisuke Ueshima', Mostafa Rabea Abdelhaleem \\ Badawy 1,2 , Giuseppe Tarantini ${ }^{1 *}$ \\ 'Department of Cardiac, Thoracic and Vascular Sciences, University of Padua Medical School, Padua, Italy \\ ${ }^{2}$ Cardiology Department, Faculty of Medicine, Minia University, Egypt
}

\section{Article Info}

\section{Article Notes}

Received: August 23, 2018

Accepted: November 6, 2018

\section{*Correspondence:}

Prof. Giuseppe Tarantini MD, PhD, FESC, Department of Cardiac, Thoracic and Vascular Science, Padova University Hospital Via Giustiniani 2, 35128 Padova, Italy; Telephone No: + 39049 8211844; Fax No: + 39049 8218158; Email: giuseppe.tarantini.1@gmail.com.

(c) 2018 Tarantini G. This article is distributed under the terms of the Creative Commons Attribution 4.0 International License.

\section{Keywords:}

Bioresorbable vascular scaffold

BRS; Absorb BRS

Complex PCl

Diffuse coronary disease.

\section{Abstract}

The optimal percutaneous treatment of diffuse coronary artery disease (CAD) remains an unsolved issue. Bioresorbable scaffold (BRS) technology has been developed to overcome the disadvantages of metallic drug-eluting stents (DES) due to their permanent struts. Through the resorption process, BRS may provide complete vascular restoration, which appears very attractive in the treatment of diffuse CAD. However, robust evidence on the use of BRS in this setting is lacking and recent data have raised concerns about the safety of this novel technology, especially when BRS are used in complex CAD or without adequate protocol implantation. This review aims at summarizing current evidence and future perspectives on Absorb BRS implantation in complex CAD, such as in distal coronary segments involvement and diffused disease.

\section{Introduction}

The optimal percutaneous treatment of diffuse coronary artery disease (CAD) is still an unsolved issue due to the well-known drawbacks of metallic drug-eluting stents (DES) and to the rising incidence of long and complex lesions in an increasingly elderly and comorbid population ${ }^{1}$. The concept of bioresorbable scaffold (BRS) technology was introduced more than two decades ago as an alternative to permanent metallic stents to provide, through the resorption process, vessel restoration, preservation of future revascularization options and reduction of late adverse events, such as stent thrombosis (ST), restenosis, and neoatherosclerosis ${ }^{2-4}$. Firstgeneration BRS, largely represented by the poly-l-lactic acid (PLLA) ABSORB (Abbott Vascular, Santa Clara, CA, USA) (Absorb BRS), have demonstrated to be non-inferior to second-generation metallic DES in low-to-moderate-complexity scenarios at mid-term follow-up of earlier randomized control trials (RCTs). However, recent metaanalyses and "real-world" registries have raised concerns about the safety of this novel technology, especially when the scaffolds were used in complex clinical and angiographic settings or without the recommended protocol implantation ${ }^{5}$. Therefore, the manufacturer halted the commercialisation of the Absorb GT1 scaffold (Abbott Vascular) with effect from September 2017. This review aims at summarizing current evidence and future perspectives of Absorb BRS implantation in complex CAD, such as in distal coronary segments involvement and diffused disease (Figure 1). 


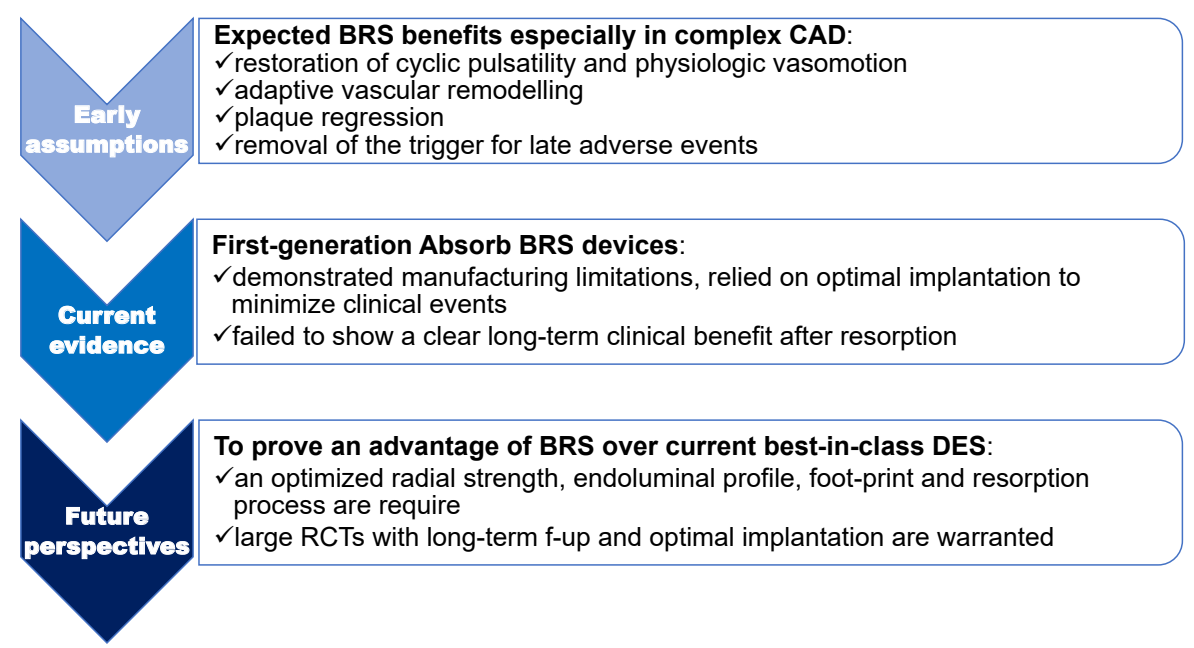

Figure 1:

\section{Evidences from Clinical Trials}

Robust evidence related to the outcomes of BRS use in the context of diffuse CAD is still lacking, since only one dedicated RCT versus a metallic II generation DES has been presented in this specific subset (Table I).

\section{Preliminary data}

The preliminary safety and efficacy of the Absorb BRS compared to current DES have been established through the short and mid-term follow-up of the trials from the ABSORB clinical development program, including low-tomoderate-complexity scenarios ${ }^{6}$.

Table I. Current evidences from Randomazid Control Trials (RCTs) on Absorb BRS use.

\begin{tabular}{|c|c|c|c|c|c|c|c|c|c|c|c|c|c|c|c|c|c|c|}
\hline \multirow[t]{2}{*}{ Study } & \multicolumn{2}{|c|}{ Participants } & \multicolumn{2}{|c|}{ DM (\%) } & \multicolumn{2}{|c|}{ ACS (\%) } & \multirow[t]{2}{*}{$\begin{array}{c}\text { Mean LL } \\
(\mathrm{mm})\end{array}$} & \multicolumn{2}{|c|}{$\begin{array}{l}\text { Adequate } \\
\text { pre } \\
\text { dilatation } \\
(\%)\end{array}$} & \multicolumn{2}{|c|}{$\begin{array}{c}\text { Adequate } \\
\text { post } \\
\text { dilatation (\%) }\end{array}$} & \multirow[t]{2}{*}{$\begin{array}{l}\text { Follow-up } \\
\text { (months) }\end{array}$} & \multicolumn{2}{|c|}{ TLF (\%) } & \multicolumn{2}{|c|}{ TLR (\%) } & \multicolumn{2}{|c|}{ ST (\%) } \\
\hline & BRS & DES & BRS & DES & BRS & DES & & BRS & DES & BRS & DES & & BRS & DES & BRS & DES & BRS & DES \\
\hline \multirow{2}{*}{ ABSORB II (11) } & \multirow{2}{*}{355} & \multirow{2}{*}{166} & \multirow{2}{*}{24} & \multirow{2}{*}{24} & \multirow{2}{*}{23} & \multirow{2}{*}{25} & \multirow{2}{*}{14} & \multirow{2}{*}{100} & \multirow{2}{*}{99} & \multirow{2}{*}{61} & \multirow{2}{*}{59} & \multirow{2}{*}{48} & 11 & 6 & 3 & 2 & 3 & 0 \\
\hline & & & & & & & & & & & & & \multicolumn{2}{|c|}{$p=0.04$} & \multicolumn{2}{|c|}{$p=0.5$} & \multicolumn{2}{|c|}{$p=0.03$} \\
\hline \multirow{2}{*}{ ABSORB III (11) } & \multirow{2}{*}{1322} & 686 & 32 & 32 & 27 & 25 & 12 & 100 & 100 & 66 & 51 & 36 & 13 & 10 & 7 & 6 & 2 & 1 \\
\hline & & 000 & 22 & 32 & 21 & $2 J$ & 10 & 100 & 100 & 00 & $J_{1}$ & 50 & $p=0$ & .06 & $p=$ & 0.3 & $p=c$ & .01 \\
\hline ABSORB IAPAN (11) & 266 & 134 & 36 & 36 & 10 & 16 & 13 & 100 & 100 & 82 & 77 & 36 & 6 & 2 & 5 & 2 & 2 & 0 \\
\hline ABSOKB JAPAIN (II) & 260 & 134 & 36 & 36 & 10 & 16 & 13 & 100 & 100 & $8<$ & 11 & 36 & $p=$ & 0.1 & $p=$ & 0.2 & $p=c$ & .01 \\
\hline ABSORB CHINA (11) & 238 & 237 & 25 & 23 & 72 & 76 & 14 & 99 & 98 & 63 & 54 & 36 & 3 & 1 & 3 & 1 & 1 & 0 \\
\hline & & & & & & & & & & & & & $p=$ & 0.3 & $p=$ & 0.3 & $p=c$ & .01 \\
\hline ARSORRIV* & 1299 & 1308 & 32 & 32 & 24 & 24 & 15 & 100 & 99 & 83 & 15 & 12 & 8 & 6 & 3 & 2 & 1 & 0 \\
\hline ADSUND IV & 1253 & 1300 & $\partial 2$ & 32 & 24 & 24 & 10 & 100 & בכ & & (J) & 12 & $p=c$ & 0.2 & $p=c$ & .08 & $p=($ & 0.1 \\
\hline COMPARF-ABSORBS & 848 & 822 & 35 & 36 & 52 & 49 & $N A$ & 97 & 79 & 91 & 58 & 12 & 5 & 4 & 3 & 2 & 2 & 1 \\
\hline CUIVIPAKE-ABSUKBS & 848 & $82 L$ & 33 & 36 & 52 & 49 & INA & 97 & 19 & 91 & 38 & 12 & $p=c$ & 0.4 & $p=$ & 0.7 & $p=0$ & .01 \\
\hline TROFI II (7) & 95 & 96 & 19 & 15 & 100 & 100 & 13 & 56 & 51 & 51 & 26 & 36 & 5 & 3 & 3 & 1 & 2 & 1 \\
\hline & & & & & & & & & & & & & $p=$ & 0.4 & $p=$ & 0.1 & $p=$ & 0.1 \\
\hline FYFRBIO (7) & 78 & 80 & 16 & 22 & 34 & 37 & $N A$ & 97 & 86 & 31 & 34 & 24 & 20 & 20 & 17 & 15 & 1 & 0 \\
\hline 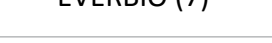 & 10 & 00 & 10 & 24 & $3_{4}$ & (19) & ה & ( & 00 & $J \pm$ & 34 & & $p=$ & 0.5 & $p=$ & 0.5 & $p=$ & 0.1 \\
\hline AIDA (7) & 924 & 921 & 19 & 17 & 54 & 54 & 19 & 97 & 91 & 74 & 49 & 24 & 10 & 9 & 7 & 5 & 4 & 1 \\
\hline AIDA (I) & 924 & 921 & & & 34 & & & & & & & 24 & $p=$ & 0.3 & $p=$ & 0.2 & $p<0$ & 001 \\
\hline
\end{tabular}

Values are presented as means or percentages.

BRS: bioresorbable vascular scaffold; DES: drug-eluting stent; DM: diabetes mellitus; ACS: acute coronary syndrome; LL: lesion length; TLF: target lesion failure; TLR: target lesion revascularization; ST: stent thrombosis.

* G.W. Stone at the Transcatheter Cardiovascular Therapeutics meeting, San Diego, September 24, 2018, unpublished $\S$ P.C. Smits at the Transcatheter Cardiovascular Therapeutics meeting, San Diego, September 24, 2018, unpublished 


\section{Longer follow-up in low-to-moderate-complexity scenarios}

Nevertheless, the initial optimism was toughened by long-term results of RCTs and several meta-analyses. At first, Absorb BRS failed to encounter its co-primary endpoint of superior vasomotor reactivity and non-inferior late luminal loss compared with the cobalt-chromium everolimus-eluting stent ${ }^{7}$. Afterwords, the device was found to be associated with higher rates of target lesion failure (TLF) compared with metallic DES, driven by an increased risk of target vessel myocardial infarction (TVMI) and target lesion revascularization and significantly higher rate of device $\mathrm{ST}^{7,8}$.

\section{Features of BRS failure}

Several meta-analysis and patient-level pooled analysis on RCTs have identified the following possible explanation for the higher risk of BRS failure compared to metallic $\mathrm{DES}^{9,10}$. First of all, the more aggressive vessel preparation required for BRS implantation, particularly in complex lesions, and the larger footprint of the current scaffolds, might lead to small side branches occlusion, with an increase in periprocedural MI. Secondly, the wider and thicker scaffold struts may also result in nonlaminar flow and altered shear stress before the scaffold is covered by neointima, increasing platelets reactivity and thus enhancing the risk for TV-MI and device thrombosis, especially with BRS implantation in very small vessels. Struts protrusion and disrupted local-wall shear stress appear also to be important determinants of neointimal growth and neoatherosclerosis. Finally, the disintegration of the polymeric scaffold struts between 1 and 3 years may result in scaffold discontinuities with endoluminal dislocation (intraluminal scaffold dismantling) which may act as substrate for thrombus formation and may be responsible for a substantial proportion of late TV-MI and ST.

\section{Role of procedural technique in moderate-to-high- complexity scenarios}

As previously suggested by several observational registries, the pooled analysis of Stone at al. from the ABSORB program's studies assessed the role of procedural technique on BRS outcomes to overcome the structural limitations of the current generation of device ${ }^{11}$. As a matter of fact, BRS implantation in properly sized vessels and optimal post-dilation were independent predictors of freedom from TLF through short and long-term follow-up. Moreover, implantation of scaffolds in very small vessels were strongly associated with ST up to 3 years of followup and an aggressive pre-dilation was associated with reduced thrombosis rate beyond 1 year. The manufacturer emphasized that the discouraging outcomes of earlier BRS
RCTs were affected by imperfect implantation technique in addition to limitations of the current device generation. In fact, optimal pre-dilation, vessel size selection and postdilation were performed in only $59.2 \%, 81.6 \%$, and $12.4 \%$ of patients, respectively. The 1-year results from the latter ABSORB 4 trial, indeed, showed a superimposable ST and TLF rates (respectively of $0.7 \%$ in BRS arm vs. $0.3 \%$ in DES arm, $\mathrm{p}=0.16$ and of $7.6 \%$ vs. $6.3 \%, \mathrm{p}=0.19$ ) in the context of better vessel selection (only $4 \%$ of patients had vessels $<2.25 \mathrm{~mm}$ by QCA) and implantation technique (post-dilation was undertaken in $84 \%$ of ABSORB BRS cases) than in prior ABSORB trials (G.W. Stone at the Transcatheter Cardiovascular Therapeutics meeting, San Diego, September 24, 2018, unpublished). Conversely, the mid-term results of the Compare Absorb Trial in a high-risk patient and/or complex lesion population not investigated in previous RCTs, as acute coronary syndromes, bifurcations, long lesions and chronic total occlusions, highlighted again the structural limitations of the current scaffold generation showing a significantly higher rate of ST in the BRS group ( $2 \%$ vs $0.6 \%, p=0.01$ ) (P.C. Smits at the Transcatheter Cardiovascular Therapeutics meeting, San Diego, September 24, 2018, unpublished). Longer-term follow-up is required to understand the true safety and efficacy profile of BRS during ( $0-3$ years) and beyond (310 years) its complete bioresorption. The beneficial effects of PSP protocol on ensuring scaffold-wall apposition may principally impact very late results ( $>1$ year).

\section{Evidences from Observational Registries}

The percutaneous treatment of complex coronary artery disease with BRS might greatly benefit from successful vessel healing over long coronary segments that may require more frequently repeat percutaneous or surgical revascularizations ${ }^{12}$. However, the structural limitations of the current scaffold generation, like the strut thickness, the larger profile and the reduced deliverability, have limited an extensive application of this technology in complex coronary lesions. Therefore, available outcome data are mainly deriving from registries (Table II).

\section{Preliminary data in complex scenarios}

The favourable initial reports on the clinical outcomes of the Absorb prompted on its use in more complex clinical and coronary anatomy conditions. Indeed, the first "realworld" prospective registries of Absorb showed acceptable outcomes, but reported a disturbing, unpredicted high ST rate possibly related to an inadequate implantation technique ${ }^{13}$.

\section{PSP concept}

Further studies have speculated that adverse events after BRS implantation may be more frequent with either scaffold under or oversizing as well as with implantation in 
Masiero G, Fovino LN, Schiavo A, Ueshima D, Abdelhaleem Badawy MR, Tarantini G. Percutaneous Coronary Intervention with Everolimus-Eluting Bioresorbable Vascular Scaffolds in

Table II. Current evidences from observational registries on Absorb BRS use in diffuse CAD.

\begin{tabular}{|c|c|c|c|c|c|c|c|c|c|c|c|}
\hline Study/First author & Study design & Participants & Settings & $\begin{array}{l}\mathrm{DM} \\
(\%)\end{array}$ & $\begin{array}{l}\text { ACS } \\
(\%)\end{array}$ & $\begin{array}{c}\text { Mean } \\
\mathrm{LL}, \mathrm{mm}\end{array}$ & $\begin{array}{c}\text { Adequate } \\
\text { pre and } \\
\text { postdilatation } \\
\text { (\%) }\end{array}$ & $\begin{array}{l}\text { Follow-up } \\
\text { (Months) }\end{array}$ & $\begin{array}{l}\text { TLF } \\
(\%)\end{array}$ & TLR (\%) & ST (\%) \\
\hline Tarantini et al. (26) & prospective & 337 & Small Vessels & 26 & 53 & 24 & 98 & 12 & 4 & 3 & 2 \\
\hline Masiero et al. (25) & prospective & 143 & Full-plastic jacket & 35 & 68 & $>56$ & 98 & 22 & 6 & 3 & 1 \\
\hline Geraci et al. (17) & prospective & $81 *$ & Long lesions & 28 & 18 & $>60$ & 80 & 12 & 14 & 10 & 4 \\
\hline Biscaglia et al. (21) & prospective & 162 & Long lesions & 28 & 54 & 44 & 96 & 12 & 9 & 7 & 2 \\
\hline Mojoli et al. (23) & prospective & 377 & Long lesions & 24 & 60 & 48 & 98 & 12 & 6 & 3 & 1 \\
\hline Testa et al. (22) & prospective & 1002 & $\begin{array}{l}\text { Long lesions/ } \\
\text { multivessel CAD }\end{array}$ & 26 & 60 & 40 & 97 & 12 & 10 & 5 & 1 \\
\hline Fam et al. (20) & prospective & 105 & СТО & 35 & 24 & 34 & 90 & 6 & 4 & 2 & 1 \\
\hline Yaginuma et al (19) & prospective & 69 & СТО & 13 & 0 & 26 & NA & 12 & 10 & 10 & 0 \\
\hline Mitomo et al (24) & retrospective & 65 & СТО & 40 & 0 & 21 & 95 & 38 & 0 & 0 & 0 \\
\hline
\end{tabular}

BRS: bioresorbable vascular scaffold; CAD: coronary artery disease; DM: diabetes mellitus; ACS: acute coronary syndrome; LL: lesion length; TLF: target lesion failure; TLR: target lesion revascularization; ST: stent thrombosis.

small vessels and suboptimal angiographic results ${ }^{14,15}$. This has led to the concept of "PSP" to optimize BRS outcomes: aggressive pre-dilation to improve vessel compliance and facilitating full scaffold expansion; appropriate vessel sizing, in particular avoiding of very small vessels in which BRS has excessive surface area coverage and polymer volume occupancy; routine, aggressive post-dilation with slightly oversized noncompliant balloons at high pressure to ensure maximize scaffold dimensions, reduce shear stress, and avoid acute malapposition ${ }^{16}$.

\section{Longer follow-up in complex scenarios}

Accordingly, subsequent larger observational registries in complex anatomies subsets have confirmed as follows: first, treatment of diffuse CAD with BRS was associated with a non-negligible rate of procedural failure, probably due to the specific features of current Absorb BRS (e.g. the strut thickness, expansion and sizing limits) which might hamper its use especially in severely calcified lesions and small vessels ${ }^{17,18}$. Secondly, the analysis of mid-term outcomes after percutaneous treatment with BRS of complex lesions PCI not reveal a significant increase of device-oriented composite end-point compared to low-tomoderate-complexity scenarios, despite high rates of TV-MI and TVR ${ }^{19,20}$. The higher rates of MI mainly driven by periprocedural events may be explained by the larger extension of CAD and once again by the structural characteristics of the device, with consequent higher risk of small branch occlusion and distal embolization ${ }^{21-23}$. Finally, these studies reported a lower rate of ST especially when a carefully lesion selection and predefined implantation technique were performed ${ }^{24-26}$. As a matter of fact, Regazzoli et al. demonstrated a very low incidence of TLF and ST at 4-year follow-up adopting a dedicated implantation strategy of BRS in a real-world cohort of patients with a high prevalence of complex lesions (69.4\% of type B2 or C lesions; $10.3 \%$ of severe calcific lesions; $26.1 \%$ of bifurcations $)^{27}$. This led to a pre and post-dilatation rate $>99 \%$, as compared to a rate of $40-72 \%$ in earlier scaffold registries. Another novel aspect was the liberal adoption of intracoronary imaging and a high rate of prolonged dual antiplatelet therapy (DAPT).

\section{Role of DAPT}

As a matter of fact, all patients who experienced late or very late ST in the former RCTs were not on DAPT, while no ST occurred in patients who never interrupted DAPT up to 3 years ${ }^{28}$. To blunt the rates of ST noted with BRS, closely related to the high-risk profile of the current device, procedural technique and late dismantling, the most recent international guidelines mandated a minimum DAPT duration of 12 months. Moreover, as suggested by available evidence on very-late follow-up, it might be reasonable prolonging DAPT beyond 12 months in patients when multiple devices are implanted or in the presence of overlapping points where 2 layers of struts further increase the tendency to thrombus formation for the mechanisms described previously ${ }^{28,29}$.

\section{Future perspectives}

In summary, meticulous lesion preparation for appropriate expansion of BRS, postdilatation with an appropriately sized noncompliant balloons to maximize the chance of adequate apposition, careful lesion evaluation with intra-vascular imaging during all steps of the procedure and maintenance of long-term DAPT in case of suboptimal procedural results were the main PCI principles that may have contributed to the achievement of better outcomes in these later registries ${ }^{30,31}$. These analyses support the potential feasibility of BRS implantation in complex scenarios with adequate lesion selection and meticulous procedural steps in order to maximize scaffold dimensions, embed struts into plaque, avoid acute malapposition, and reduce shear stress which may thus have favorable effects on clinical outcomes during the 
scaffolds healing and resorption phases, even as late as 3 years ${ }^{32}$. Moreover, this data implies that further efforts to improve scaffold design and optimize BRS implantation are required and justify further research including direct comparison with standard metal drug-eluting stents and analysis of angiographic, intravascular imaging and clinical results at long-term follow-up ${ }^{33}$. Nevertheless, the presence of diffuse CAD involving complex lesions not appropriate for pure scaffolding PCI (e.g. long lesions with reference vessel diameters too large or small or involving an ostial or severely calcified segment) does not necessarily mean that the concept of "leaving left behind" should be set aside. Accordingly, a hybrid coronary revascularization with an offpump beating-heart revascularization procedure followed by a staged PCI suitable for BRS optimal implantation or a metal free hybrid strategy of BRS for larger size vessels and DEB for smaller sized vessels could be considered ${ }^{34,35}$.

\section{Conclusions}

Restoration of cyclic pulsatility and physiologic vasomotion, adaptive vascular remodelling, plaque regression, and removal of the trigger for late adverse events were expected BRS benefits over current generation metallic DES especially in complex CAD. However, firstgeneration Absorb BRS devices demonstrated significant manufacturing limitations, relied on optimal implantation to minimize clinical events and failed to show a clear longterm clinical benefit after resorption. A new generation of BRS with an optimized radial strength, a sleeker endoluminal profile, a smaller foot-print, and a resorption process not interacting with vessel wall are key requisites to improve outcomes. Moreover, well conducted large RCTs with long-term follow-up and optimal implantation practices are warranted to determine whether the differences with metallic stent may be lessened by structural improvements, procedural precautions and adequate DAPT and to prove a tangible advantage of BRS over current best-in-class DES (i.e., angina reduction, vasomotion, TLF). To fulfil their promises and be successfully adopted in everyday clinical practice, BRS must meet these standards of evidence.

\section{References}

1. Boden WE, O'Rourke RA, Teo KK, et al. The evolving pattern of symptomatic coronary artery disease in the United States and Canada: baseline characteristics of the Clinical Outcomes Utilizing Revascularization and Aggressive DruG Evaluation (COURAGE) trial. Am J Cardiol 2007;99:208-12.

2. Serruys PW, Garcia-Garcia HM, Onuma Y. From metallic cages to transient bioresorbable scaffolds: change in paradigm of coronary revascularization in the upcoming decade? Eur Heart J 2012;33(1):16$25 \mathrm{~b}$

3. Indolfi C, De Rosa S, Colombo A. Bioresorbable vascular scaffolds - basic concepts and clinical outcome. Nat Rev Cardiol. 2016 Dec;13(12):719-729. doi:10.1038/nrcardio.2016.151. Epub 2016 Sep 29. Review. PubMed PMID: 27681575

4. Kereiakes DJ, Onuma Y, Serruys PW, Stone GW. Bioresorbable vascular scaffolds for coronary revascularization. Circulation 2016;134:16882

5. Masiero G, Mojoli M, Ueshima D, Tarantini G. Current concepts on coronary revascularization using BRS in patients with diabetes and small vessels disease. J Thorac Dis. 2017 Aug;9(Suppl 9):S940-S949. doi: 10.21037/jtd.2017.06.36. Review. PubMed PMID: 28894600; PubMed Central PMCID: PMC5583088.

6. Stone GW, Gao R, Kimura T, et al. 1-year outcomes with the Absorb bioresorbable scaffold in patients with coronary artery disease: a patient-level, pooled meta-analysis. Lancet. 2016 Mar 26;387(10025):1277-89. doi:10.1016/S0140-6736(15)01039-9. Epub 2016 Jan 27. PubMed PMID: 26825231.

7. Felix CM, van den Berg VJ, Hoeks SE, et al. Mid-term outcomes of the Absorb BVS versus second-generation DES: A systematic review and meta-analysis. PLoS One. 2018 May 9;13(5):e0197119. doi: 10.1371/ journal.pone.0197119. eCollection 2018. PubMed PMID: 29742143; PubMed Central PMCID: PMC5942828.

8. Ali ZA, Serruys PW, Kimura T, et al. 2-year outcomes with the Absorb bioresorbable scaffold for treatment of coronary artery disease: a systematic review and meta-analysis of seven randomised trials with an individual patient data substudy. Lancet. 2017. https://doi.org/10. 1016/S0140-6736(17)31470-8 PMID: 28732815.

9. Ali ZA, Gao R, Kimura T, et al. Three-Year Outcomes With the Absorb Bioresorbable Scaffold: Individual-Patient-Data Meta-Analysis From the ABSORB Randomized Trials. Circulation. 2018 Jan 30;137(5):464479. doi: 10.1161/CIRCULATIONAHA.117.031843. Epub 2017 Oct 31. PubMed PMID: 29089314.

10. Polimeni A, Weissner M, Schochlow K, et al. Incidence, clinical presentation, and predictors of clinical restenosis in coronary bioresorbable scaffolds. JACC Cardiovasc Interv 2017; 10: 1819-27.

11. Stone GW, Abizaid A, Onuma Y, et al. Effect of Technique on Outcomes Following Bioresorbable Vascular Scaffold Implantation: Analysis From the ABSORB Trials. J Am Coll Cardiol. 2017 Dec 12;70(23):28632874. doi: 10.1016/j.jacc.2017.09.1106. Epub 2017 Oct 31. PubMed PMID: 29100704.

12. Tarantini G, Saia F, Capranzano P, et al. [SICI-GISE Position paper: Use of Absorb BVS in clinical practice]. G Ital Cardiol (Rome). 2016 Oct;17(10 Suppl 1):28S-44.

13. Capodanno D, Gori T, Nef H, et al. Percutaneous coronary intervention with everolimus-eluting bioresorbable vascular scaffolds in routine clinical practice: early and midterm outcomes from the European multicentre GHOST-EU registry. EuroIntervention. 2015;10:1144-53

14. Ishibashi Y, Nakatani S, Sotomi Y, et al. Rela- tion between bioresorbable scaffold sizing using QCA-Dmax and clinical outcomes at 1 year in 1,232 patients from 3 study cohorts (ABSORB Cohort B, ABSORB EXTEND, and ABSORB II). J Am Coll Cardiol Intv 2015;8:1715-26.

15. Puricel S, Cuculi F, Weissner M, et al. Bioresorbable coronary scaffold thrombosis: multicenter comprehensive analysis of clinical presentation, mechanisms, and predictors. J Am Coll Cardiol 2016;67:921-31.

16. Ortega-Paz L, Capodanno D, Gori T, et al. Pre- dilation, sizing and post-dilation scoring in patients undergoing everolimus-eluting bioresorbable scaf- fold implantation for prediction of cardiac adverse events: development and internal validation of the PSP score. EuroIntervention 2017;12:2110-7

17. Geraci S, Kawamoto H, Caramanno G, et al. Bioresorbable EverolimusEluting Vascular Scaffold for Long Coronary Lesions: A Subanalysis of the International, Multicenter GHOST-EU Registry. JACC Cardiovasc Interv. 2017 Mar 27;10(6):560-568. doi: 10.1016/j.jcin.2016.12.013. Epub 2017 Mar 1. PubMed PMID: 28259663.

18. La Manna A, Chisari A, Giacchi G, et al. Everolimus-eluting bioresorbable vascular scaffold versus second generation drugeluting stents for percutaneous treatment of chronic total coronary 
occlusions: Technical and procedural outcomes from the GHOST-CTO registry. Catheter Cardiovasc Interv. 2016 Nov 15;88(6):E155-E163. doi: 10.1002/ccd.26397. Epub 2016 Jan 12. PubMed PMID: 26756959.

19. Yaginuma K, Moehlis H, Koch M, at el. Bioresorbable vascular scaffolds for complex chronic total occlusions. Cardiovasc Revasc Med. 2018 Jun 21. pii: S1553-8389(18)30266-5. doi: 10.1016/j.carrev.2018.06.017. [Epub ahead of print] PubMed PMID: 30025659.

20. Fam JM, Ojeda S, Garbo R, et al. Everolimus-eluting bioresorbable vascular scaffolds for treatment of complex chronic total occlusions. EuroIntervention. 2017 Jun 20;13(3):355-363. doi: 10.4244/ EIJ-D-16-00253. PubMed PMID: 28218604.

21. Biscaglia S, Ugo F, Ielasi A, Secco GG, Durante A, D’Ascenzo F, et al. Bioresorbable Scaffold vs. Second Generation Drug Eluting Stent in Long Coronary Lesions requiring Overlap: A Propensity-Matched Comparison (the UNDERDOGS study). Int J Cardiol. 2016;208:40-5.

22. Testa L, De Carlo M, Petrolini A, et al. One-year clinical results of the Italian diffuse/multivessel disease ABSORB prospective registry (ITDISAPPEARS). EuroIntervention. 2017 Jul 20;13(4):424-431. doi: 10.4244/EIJ-D-17-00246. PubMed PMID: 28504219.

23. Tarantini G, Mojoli M, Masiero G, et al. Clinical outcomes of overlapping versus non-overlapping everolimus-eluting absorb bioresorbable vascular scaffolds: An analysis from the multicentre prospective RAI registry (ClinicalTrials.gov identifier: NCT02298413). Catheter Cardiovasc Interv. 2018 Jan 1;91(1):E1-E16. doi: 10.1002/ccd.27095 Epub 2017 May 13. PubMed PMID: 28500737.)

24. Mitomo S, Naganuma T, Fujino Y, et al. Bioresorbable Vascular Scaffolds for the Treatment of Chronic Total Occlusions: An International Multicenter Registry. Circ Cardiovasc Interv. 2017 Jan;10(1). pii: e004265. doi: 10.1161/CIRCINTERVENTIONS.116.004265. PubMed PMID: 28069611.

25. Tarantini G, Masiero G, Fovino LN, et al. "Full-plastic jacket" with everolimus-eluting Absorb bioresorbable vascular scaffolds: Clinical outcomes in the multicenter prospective RAI registry (ClinicalTrials. gov Identifier: NCT02298413). Int J Cardiol. 2018 Sep 1;266:67-74. doi: 10.1016/j.ijcard.2018.01.063. PubMed PMID: 29887475.

26. Tarantini G, Masiero G, Barioli A, et al. Absorb bioresorbable vascular scaffold vs. everolimus-eluting metallic stent in small vessel disease: A propensity matched analysis of COMPARE II, RAI, and MAASSTADABSORB studies. Catheter Cardiovasc Interv. 2018 Mar 7. doi: 10.1002/ccd.27522. [Epub ahead of print] PubMed PMID: 29513403.
27. Regazzoli D, Latib A, Ezhumalai B, et al. Long-term follow-up of BVS from a prospective multicenter registry: Impact of a dedicated implantation technique on clinical outcomes. Int J Cardiol. 2018 Jun 25. pii: S0167-5273(18)30495-9. doi: 10.1016/j.ijcard.2018.06.094. [Epub ahead of print] PubMed PMID: 29983253.

28. Capodanno D. Bioresorbable Scaffolds in Coronary Intervention: Unmet Needs and Evolution. Korean Circ J. 2018 Jan;48(1):24-35. doi: 10.4070/kcj.2017.0194. Review. PubMed PMID: 29322695; PubMed Central PMCID: PMC5764868.

29. Capodanno D, Angiolillo DJ. Antiplatelet therapy after implantation of bioresorbable vascular scaffolds: a review of the published data, practical recommendations, and future directions. JACC Cardiovasc Interv 2017;10:425-37.

30. Ellis SG, Steffenino G, Kereiakes DJ, Stone GW, van Geuns RJ, Abizaid A, et al. Clinical, angiographic, and procedural correlates of acute, subacute, and late absorb scaffold thrombosis. JACC Cardiovasc Interv. 2017;10(18):1809-15.

31. Polimeni A, Gori T. Bioresorbable vascular scaffold: a step back thinking of the future. Postepy Kardiol Interwencyjnej. 2018;14(2):117-119. doi: 10.5114/aic.2018.76401. Epub 2018 Jun 19. Review. PubMed PMID: 30008762; PubMed Central PMCID: PMC6041831.

32. Bangalore S, Bezerra HG, Rizik DG, et al. The State of the Absorb Bioresorbable Scaffold: Consensus From an Expert Panel. JACC Cardiovasc Interv. 2017 Dec 11;10(23):2349-2359. doi: 10.1016/j. jcin.2017.09.041. Review. PubMed PMID: 29216997.

33. Costa JR Jr, Abizaid A. Bioresorbable Coronary Scaffolds: Deployment Tips and Tricks and the Future of the Technology. Methodist Debakey Cardiovasc J. 2018 Jan-Mar;14(1):42-49. doi: 10.14797/mdcj-141-42. Review. PubMed PMID: 29623171; PubMed Central PMCID: PMC5880559.

34. Mikus E, Grattoni C, Flavio F, et al. Hybrid coronary artery revascularization: Initial experience of a single centre. Eur Heart J Suppl. 17. A38-A42. 10.1093/eurheartj/suv015.

35. Tanaka A, Jabbour RJ, Mitomo S, et al. Hybrid Percutaneous Coronary Intervention With Bioresorbable Vascular Scaffolds in Combination With Drug-Eluting Stents or Drug-Coated Balloons for Complex Coronary Lesions. JACC Cardiovasc Interv. 2017 Mar 27;10(6):539547. doi: 10.1016/j.jcin.2016.12.285. Review. PubMed PMID: 28335892. 